\title{
Research on the Tourism Interactive Development of the Yangtze River Delta City Circle under the Perspective of Regional Integration
}

\author{
LIN ZANGEN \& ZHAO LIMING \\ College of Management and Economics, Tianjin University, Tianjin, China
}

\begin{abstract}
This thesis firstly analyzes the tendency of interactive development of Yangtze River Delta city circle tour under the perspective of regional integration and draws a conclusion that "regional tourism" and "tourism regionalization" have continually developed in the Yangtze River Delta city circle. Then, taking three major cities Shanghai, Nanjing, Hangzhou for example, this thesis has a discussion on the paths of interactive development of urban tourism under the perspective of regional integration.
\end{abstract}

KEYWORD: Yangtze River Delta City Circle; Tourism Interactive Development; Regional Integration

\section{INTRODUCTION}

Since the adoption of the reform and opening up policy, China's tourism industry has developed at a fast speed. As China's first metropolis economic circle, Yangtze River Delta's tourism industry developed even more rapidly. Therefore, many cities in Yangtze River Delta area are starting to change the tourism development strategy, from competition development into regional cooperation. For the city in the same area, how to achieve the tourism resources complementation and "leveraging off" in the competition of tourism market and how to accomplish urban tourism interactive development to improve the whole tourism economic level in a city circle have already become the key topics in the field of tourism economic development of the city circle. Within the Yangtze River Delta, the main economic body, the cooperation between cities is obvious, which provides the impetus for the tourism interactive development of Yangtze River Delta city circle. In this paper, making Yangtze River Delta city circle as the researching object, the writer does some researches on the momentum of tourism interactive development in Yangtze River Delta city circle under the perspective of regional integration and tries to find the paths for tourism interactive development.

\section{INTERACTIVE DEVELOPMENT TENDENCY OF CITY TOURISM IN THE YANGTZE RIVER DELTA}

Because of the highly intensive cities in Yangtze River Delta area, this region has become the biggest economic circle in China. Cities in Yangtze River Delta are distributed in several belt areas and up to now there have been three core cities-Shanghai, Nanjing and Hangzhou. At present, regional cooperation in Yangtze River Delta has become increasingly close which accelerates the process of regional integration in this area. The traffic facilities in Three City Areas (Hangzhou-Nanjing, ShanghaiHangzhou and Hangzhou-Nanjing) are getting more and more robust, which contributes to the rising of Hangzhou-Nanjing area, the development of the whole Yangtze River Delta has expanded more widely, from axis to plain. (Figure 1).

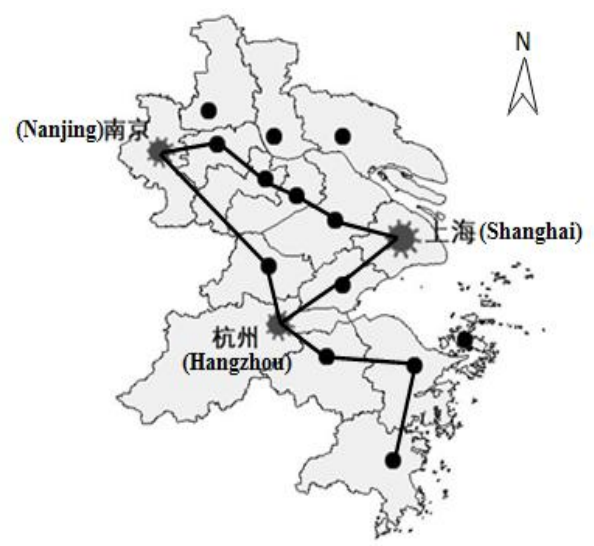

Figure1. Developing axis of the cities in Yangtze River Delta 


\subsection{Regional tourism development should be based on the urban development}

Obviously there is a great connection between the level of regional tourism economy and urban economy. The urbanization of Yangtze River Delta is in a comparatively high level with the rate of urbanization reaching $56 \%$ by the year 2012 , which leads to the forming of an urban agglomeration system with a number of cities tightly connected. With continuous agglomeration development of the industries in Yangtze River Delta and the improvement of regional planning, many cities in this area have achieved the pattern of economic integration development. For example, along the Yangtze River, Suzhou, Wuxi, Changzhou, Zhenjiang and Nanjing have already been joined together, which provide an essential foundation for the centralization of regional economy and the agglomeration development of the industry.

In addition, the model of Yangtze River Delta area also gives a good example to Chinese modern tourist complex areas. It possesses two properties tourism demand center and tourism supply center. In 2012, the total number of inbound tourists received only by Shanghai, Nanjing, Hangzhou, Suzhou, Wuxi and Nanjing reached 17,578,600 creating a total income of 12.209 billion U.S. dollars of foreign exchange, accounting for $71.5 \%$ and $71.7 \%$ of the total amount of Jiangsu, Zhejiang and Shanghai respectively. Thus, it can be seen that the role of city is becoming more and more important in the development of regional urban tourism. The developed urban tourism accelerates the development of modern tourism and the process of internationalization of Yangtze River Delta area.

\subsection{Tourism urbanization of Yangtze River delta boosted the tourism integration}

Yangtze River Delta economic development of urban tourism accelerates the rate of urbanization. Firstly, the city has more developed recreational facilities, accommodation, catering etc., providing the material guarantee for the traveling. Secondly, influenced by the transportation convenience, leisure time and other factors, most of the urban residents prefer to travel in the city or suburbs near the city. Meanwhile, in order to adapt to the trend that there is a growing demand for traveling among the urban residents, the cities and the suburbs nearby will correspondingly increase their investments in tourism facilities. All these further accelerate the urbanization of the tourism. In the Yangtze River Delta area, many tourist attractions are within the city, such as West Lake in Hangzhou, Shanghai Oriental Pearl TV Tower, Changzhou Dinosaur Park; even as some ancient towns, like Zhouzhuang etc. are mostly in the suburbs near the city and exposed to the radiation of the city, they have a city tendency. In addition, the Yangtze River Delta region has well-developed road network. Water, road and rail transportation are developed too, which not only provides a great convenience to the distribution of tourists, but also help expand the radiation scope of Yangtze River Delta city tour, further promoting the integration development of the Yangtze River Delta regional tourism.

\subsection{Competitive developments in Yangtze River delta propell the continuous regionalization of urban tourism}

With the reform of market economic system , tourism industry of the Yangtze River Delta gradually become market-oriented, so the competition of tourism market in this area is getting more and more fierce. Making the region as a platform for developing, the integration of regional resources as a direction, the exploration of integrated tourism products as a key point, and the creation of an overall image of Yangtze River Delta tourism as an objective, Yangtze River Delta area relocated the tourism industries in different cities, which promoted the urban tourism competition from chaos to order. Not only can this achievement promote inter-provincial tourism development, but put forward the accomplishment of regionalization in Yangtze River Delta urban area.

\subsection{A regional tourism integration model- "multiple poles and mesh development"}

As the economy in Yangtze River Delta developing at a high speed and the level of urbanization in this area being increasingly improved, several urban economic circles, with the large city as a pole, are coming out. Meanwhile with the help of developed transportation network and high-concentrated industrial developing model, Yangtze River Delta has finished the first step in the formation of "multiple poles and mesh development". This regional economic development model inevitably leads to a new trend of Yangtze River Delta tourism developing that is characterized by multiple poles and mesh development. With the deepening of regional integration and cooperating, the urban tourism complementing and jointly developing will also continue, which further strengthen the formation of the "multiple poles and mesh development" regional tourism integration model. With the growing convergence of regional tourism economy, the pole advantages of tourism and economic center will continue to be weakened and the Yangtze River Delta regional economic centers tend to be decentralized. For Shanghai, Hangzhou and Nanjing, the three core cities in Yangtze River Delta, from 2005 to 2012, there seem to be a downward trend in the following four indicators, the centrality of the 
inbound tourist, foreign exchange earnings, domestic tourist and domestic tourism revenue.

\section{DISCUSSION ON THE URBAN TOURISM INTERACTIVE MODE IN YANGTZE RIVER DELTA AREA - TAKING SHANGHAI, NANJING AND HANGZHOU FOR EXAMPLE}

\subsection{Similarity of Shanghai - Hangzhou - Nanjing urban tourism development}

City groups in Yangtze River Delta are roughly distributed in Nanjing - Shanghai - Hangzhou Ningbo area, in a shape of "zigzag". In the context of the regional integration development of Yangtze River Delta, it is necessary to put forward the interactive development of urban tourism in this area.

Firstly, Shanghai, Nanjing and Hangzhou are close to each other in geographic distance. The transportation advantages are outstanding in these areas where there are the Grand Canal, Yangtze River and other developed waterway transport; there are Shanghai-Nanjing, Hangzhou-Nanjing, Shanghai-Hangzhou high-speed railways and crisscrossed road traffic. Currently it is planning to construct a inter-city railway, which will make the traffic in the three cities more convenient and provide more adequate conditions for the ShanghaiNanjing -Hangzhou tourism interaction.

Secondly, although the three cities have a competitive relationship in terms of tourism resources, there is no lack of complementary functions in each two. Shanghai is oriented to build urban tourism attractions. Nanjing mainly has historical and cultural attractions. Hangzhou is known to its scenery tourism attractions, so the tourism resources in the three cities cannot be easily replaced.

Thirdly, as the tourism economy in the three cities-Shanghai Nanjing and Hangzhou keeps on growing, the inbound tourism market and China's domestic tourism market are developing rapidly. In Shanghai, Nanjing and Hangzhou, the number of domestic tourists in China and China's domestic tourism revenue are in an upward trend; In Nanjing and Hangzhou, the number of inbound tourists and tourism foreign exchange earnings also increased. From the writer's point of view it is the integration development of regional tourism in Yangtze River Delta that make the inbound tourism market in Shanghai develop downward. According to the developing trend of tourism market in the three cities, it is concluded that cities are complementary in tourism economy, which provides the impetus for the further development of the Shanghai-NanjingHangzhou tourism interaction.

\subsection{Calculation of urban tourism interactive connection degree in Shanghai, Nanjing and Hangzhou}

According to the analysis above, the three cities are complementary in the tourism location, tourism resources, tourism economy and other aspects, so they can certainly develop interactively. By the following quantitative analysis, the tourism interactive connection degree can be measured.

Referring to the thought of Fangfalin and others', and combining with some relevant experiences, this paper calculated the connection degree of tourism interaction between Shanghai, Nanjing and Hangzhou. The connection degree of tourism economy can reflect the mutual radiation between each two cities, which further reflects the development of regional tourism economic network. The tourism interactive connection degree formula is as follow:

$$
R_{i j}=\left(P_{i} V_{i}\right)^{1 / 2}\left(P_{j} V_{j}\right)^{1 / 2} / D_{i j}{ }^{2}
$$

In this formula, $R_{i j}$ stands for the degree of tourism interactive connection between city $i$ and city $j ; P_{i}$ and $P_{j}$ represents the total number of tourists in city $i$ and city $j$ respectively ; $V_{i}$ and $V_{j}$ represents each city 's total domestic tourism revenues ; $D_{i j}$ stands for the transportation distance between city $i$ and city $j$, which is expressed by the miles of the main highway between two cities and the miles are measured by Google Earth software .

According to equation (1), we get a series of tourism interactive connection degrees of Shanghai, Nanjing and Hangzhou in the year 2005, 2010 and 2012. The results show that the degrees of tourism interactive connection between the three cities are high, and after the year 2010 the tourism interactive connection degrees have exceeded 100 , especially in Hangzhou and Shanghai the degrees have already exceeded 100 in the year 2005. Until the year 2012 the tourism interactive connection degree between any two of the cities has been close to 900 . According to the data, it can be concluded that there is a high potential for the tourism interaction of the three cities.

\subsection{The Developing Paths to the Urban Tourism Interaction From the Perspective of Regional Integration}

In recent years, as the rising of tourism markets in the surrounding cities and the acceleration of the regional integration process, it is more favorable for the cities to develop tourism interaction, so the 
tourism competitive and cooperative relationship in the three cities becomes more effective as well.

\subsubsection{The Interaction of Regional Tourism Devel- opment Concept}

According to economic theory, the tourism interaction of the three cities can be carried out on condition of mutual benefit or reciprocity, finally achieving "win-win" objective. However in practice the "win-win" concept has not be completely formed in the three cities, in their tourism cooperation, each city still more focus on its self-interests. For example, in the planning of urban tourism, there is not adequate content related to regional integration and there is seldom inter-city coordination. With the process of urbanization in Shanghai, Nanjing and Hangzhou accelerating, they badly need to construct a competitive and cooperative relationship between city and regional integration and update and deepen the concept of regional tourism development. They should put more emphasis on the tourism interactive development at the level of regional integration. Only in this way can their own advantages and regional advantages be given full play when facing a broader market and the core competitiveness of the overall tourism in Shanghai, Nanjing and Hangzhou area be enhanced.

\subsubsection{The Interaction of Regional Tourism Mecha- nism}

In Shanghai's "second five" tourism planning, it is proposed to make Shanghai an international metropolis tourist destination, which cannot be maintained without the symbiosis cooperation with the Yangtze River Delta tourist under the acceleration of regional integration. For Hangzhou and Nanjing, the city who can better be compatible with Shanghai can develop its tourism economy faster and more effectively. Therefore, cooperating with the tourism enterprises in Shanghai is considered to be an important development strategy adopted by many enterprises in Nanjing and Hangzhou, and in this way the mechanisms for the tourism coordination of Shanghai, Nanjing and Hangzhou are constantly forming. The tourism management systems for each administrative region have not been compatible and the coordination and cooperation mechanisms are lack of institutional guarantee. Thus, the three cities should construct an orderly tourism cooperative mechanism and establish coordinating bodies for tourism cooperation with a view of regional integration.

\subsubsection{The Interaction of Regional Tourism Product Research and Development}

Currently, the inter-regional cooperation model of tourism product design and R\&D hasn't been formed; especially the tourism product $R \& D$ is very independent, so that regional tourism resources cannot be fully coordinated that is not conducive to the optimal allocation of the regional resources. To this end, the three cities should get rid of the administrative constraints and aim to accomplish the resource sharing and tourists' interaction. In the process of tourism product $\mathrm{R} \& \mathrm{D}$, the three cities should be based on each own tourism characteristics and be guided towards individualized and differentiation competition. Joining the regional enterprises union and integrating the existing decentralized and complementary attractions, the three cities continuously improved the tourism quality and optimize the traveling routes in order to accomplish a comprehensive tourism system based on the sightseeing, mainly forced by leisure recreation and featured by special tour. Wellqualified and featured intercity tourism products are increasingly coming out, which enhance the scale effect of urban tourism in Shanghai, Nanjing and Hangzhou.

\subsubsection{The Interaction of Regional Tourism Market- ing}

Marketing tourism is one of the important trends in current global tourism development. According to the Statistics, about $65 \%$ of the tourists who have visited the Yangtze River Delta region are from the inside of this region, so it is obvious that the place where the tourists are from and the tourists' traveling destination are always the same, which means the three cities have the same target market, so the cooperative marketing is an optional approach for them. Through sharing the marketing channel and network information, working together to plan tourism publicity, jointly holding large-scale tourism festival activities, together naming the slogan for the tourism product, drawing up the logo of the tourism image and other ways to cooperation, the three cities could construct a mutual tourism marketing platform, aiming to constantly promote the interaction of tourism resources information, to improve the utilization of tourism infrastructure, to enhance the regional tourism brand position and to expand "the same city effect" in the tourism marketing.

\section{CONCLUSION}

In this paper, through a combination of qualitative and quantitative analysis, the writer did a research on the Interactive Development of the Yangtze River Delta City Circle Tour under the perspective of regional integration and mainly took Shanghai, Nanjing and Hangzhou for example, in order to have a discussion on the paths to urban tourism interactive development. According to the comprehensive analysis in this paper, the writer concluded that in 
Yangtze River Delta City Circle, the trend of "regionally tourism-oriented" and "tourism regionalization" is unalterable, namely there being broad space for urban tourism interactive development. Shanghai, Nanjing and Hangzhou provide an excellent interactive tourism development paradigm for Yangtze River Delta region, so the cities within the Yangtze River Delta should take advantage of each own tourism resources to conduct tourism cooperative interaction with the surrounding cities, which not only help expand its regional tourism influential area, but also enhance the impact of tourism, finally achieving the convergence of city circle tourism in Yangtze River Delta area.

\section{REFERENCES}

[1] Zou Guangyong,Liu Mingyu. Regional Tourism Integration Can Be Achieved? - Based on Research SPNE Salop Model. Tourism Tribune, 2013, 28 (12): 46 -53.

[2] Tazim B, Jamal \& Donald Getz. Collaboration theory and community tourism planning. Annals of Tourism Research, 1995, 22 (1):186-204.

[3] Li Weiqing. Evaluation on the Clusters Significance and the Performance Level of Yangtze River Delta Tourism Industry. Business Times, 2013 (19): 142-145.

[4] Lee C, Kwon K. Importance of secondary Impact of tourism receipts on the South Korea Economy. Journal of Travel Research, 1995(34): 50-54.

[5] Murphy L, Moscardo G \& Benckendorff P. Using brand personality to differentiate regional tourism destinations. Journal of Travel Research, 2007, 46(1): 5-14. 